Original Research Paper

\title{
Modelling and Analysis of Voltage Mode Controlled Luo Converter
}

\author{
Divya Navamani Jayachandran, Vijayakumar Krishnaswamy, \\ Lavanya Anbazhagan and Karthikeyan Dhandapani
}

Department of EEE, SRM University, India

\section{Article history}

Received: 27-08-2014

Revised: 09-04-2015

Accepted: 06-10-2015

Corresponding Author: Divya Navamani Jayachandran Department of EEE, SRM

University, India

Email: divyanavamani.j@ktr.srmuniv.ac.in

\begin{abstract}
This paper presents the analysis of open loop power stage dynamics relevant to voltage mode control for elementary Luo DC-DC converter for certain specific applications like Hybrid Electric Vehicles, fuel cell vehicles. A comparative analysis is carried out on positive output super lift series of converters to evaluate voltage gain, output voltage ripple, stresses on the switches and efficiency. The most suitable converter is modelled and verified using State Space average method and Circuit averaging technique. The transfer function from duty cycle to output voltage and input voltage to output voltage are derived. The transfer function can be used in modelling the complete luo converter when voltage mode control is used. Also a simple efficiency modelling technique is proposed with computer simulation using MATLAB/SIMULINK that confirms the predicted results.
\end{abstract}

Keywords: Luo Converter, Small Signal Transfer Function, Efficiency Modeling, Voltage Mode Control

\section{Introduction}

Electrical power systems in future hybrid and fuel cell vehicles may employ three voltage $(14 \mathrm{~V}, 42 \mathrm{~V}$ and High Voltage (HV)) nets. High step up DC-DC converter is necessary for many applications such as FCV, HEV to step up the voltage to high level .One of the key blocks inside hybrid electric vehicles is the DC-DC converter for auxiliary power supply of electric loads. The nominal voltage at the low voltage side of one input is $12 \mathrm{~V}$ and can vary from 8 to $16 \mathrm{~V}$ during charging and discharging. The nominal high-side voltage is $288 \mathrm{~V}$, with an operating range from $255-425 \mathrm{~V}$. Nominal charging and discharging power is $1.5 \mathrm{~kW}$. Switching frequency is $70-$ $100 \mathrm{kHz}$. Battery power systems often stack cells in series to achieve higher voltage. However, sufficient stacking of cells is not possible in many high voltage applications due to lack of space. Boost converters can increase the voltage and reduce the number of cells. The NHW20 model Toyota Prius HEV uses a $500 \mathrm{~V}$ motor. Without a boost converter, the Prius would need nearly 417 cells to power the motor. However, a Prius actually uses only 168 cells and boosts the battery voltage from 202 to $500 \mathrm{~V}$. Further with the use of relift converter, use of 3 batteries is enough to power up to $500 \mathrm{~V}$. Voltage Lift (VL) technique is a popular method widely used in electronic circuit design. It has been successfully employed in $\mathrm{dc} / \mathrm{dc}$ converter applications in recent years and opened a way to design high voltage gain converters.
Four series Luo converters (Luo, 1999a; 1999b; 2000; Luo et al., 2002; Luo and Ye, 2001) are the examples of VL technique implementations.

Dynamic behavior modeling of nonlinear Pulse Width Modulated (PWM) dc-dc converters has been studied in previous literature (Middlebrook and Cuk, 1970; Severns and Bloom, 1985; Polivka et al., 1986; Vorpérian, 1990; Kazimierczuk and Czarkowski, 1993). Modeling of open-loop as well as closed-loop PulseWidth Modulated (PWM) dc-dc converters is necessary for dynamic and stability analysis of non-linear PWM $\mathrm{dc}-\mathrm{dc}$ converters. Accurate modelling of the power stage is necessary to determine closed-loop transfer functions.

\section{Modeling Methods}

Modeling is the representation of physical behavior by mathematical means. The Simplified models yield physical insight, allow in design system to operate in specified manner. After basic insight has been gained, model can be refined to account for some of the previously neglected phenomenon. The most commonly used modeling methods are: State space averaging: Matrix based approach which gives insight into quantitative nature of basic averaging approximation and Circuit averaging technique: Method based on equivalent circuit manipulations, resulting in a single equivalent linear circuit model of power stage. 


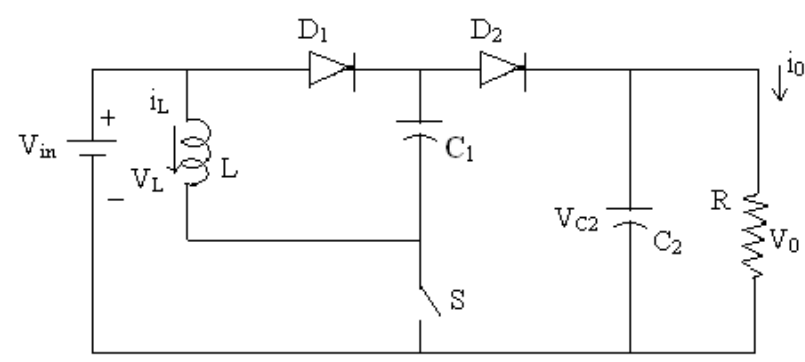

Fig. 1. Elementary luo converter

The reasons for deriving transfer functions are:

- To analyze the stability and control loop behavior

- To visualize the influence of supply voltage or load changes

- To minimize the influences of supply voltage variations and load changes on the output voltage of a DC/DC converter loop, compensation designs are necessary. The quality of this control circuit design defines the stability of the entire DC/DC converter

- A loop is stable when its phase reaches $-180^{\circ}$ after the gain has dropped below $1(=0 \mathrm{~dB})$. If this condition is not fulfilled a frequency exists at which the gain is higher than 1 and the phase shift is exactly $180^{\circ}$

- The impedance measurement could help evaluate possibility of DC/DC converter front-end oscillation

- The duty cycle to output transfer function carries the information needed to determine the structure of the voltage feed- back compensation

- Input to output transfer function is necessary to analyze the audio susceptibility

\section{Modelling of Elementary Luo Converter}

\section{Using State Space}

\section{Apply KVL Determine A, B, C, E Matrices}

Figure 1 shows elementary Luo converter. In this positive output Luo converter, there are two states i.e., when switch is on and when switch is off. During each state we write the following Equation 1 and 2:

$x^{\prime}=A_{1} x+B_{1} V_{d}$ during $d T_{s}$

$x^{\prime}=A_{2} x+B_{2} V_{d} \quad$ during $(1-d) T_{s}$

where, $A_{1}+A_{2}$ are state matrices and $B_{1}$ and $B_{2}$ are vectors. Let $x_{1}$ be inductor current, $x_{2}$ represent voltage across capacitor $1, x_{3}$ represent voltage across capacitor 2. Figure 2 and 3 shows the turn on and turn off condition of luo converter.

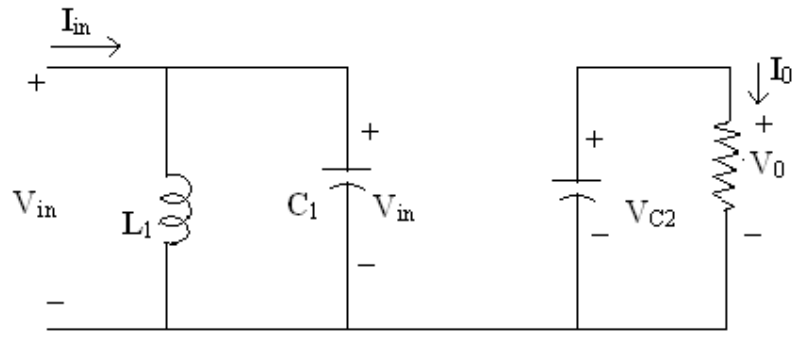

Fig. 2. On state condition

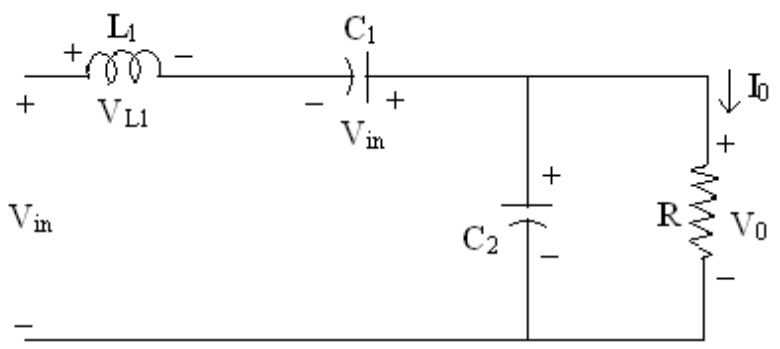

Fig. 3. Off state condition

For turn on:

$$
\left(\begin{array}{l}
x_{1}^{1} \\
x_{2}^{1} \\
x_{3}
\end{array}\right)=\left(\begin{array}{ccc}
0 & \frac{1}{L} & 0 \\
\frac{-1}{C_{1}} & \frac{-1}{\left(R_{i} C_{1)}\right.} & 0 \\
0 & 0 & \frac{-1}{R C_{2}}
\end{array}\right)\left(\begin{array}{c}
x_{1} \\
x_{2} \\
x_{3}
\end{array}\right)+\left(\begin{array}{c}
0 \\
\frac{1}{\left(R_{i} C_{1}\right.} \\
0
\end{array}\right) V_{d}
$$

For turn off:

$$
\begin{gathered}
\left(\begin{array}{l}
x_{1}^{1} \\
x_{2}^{1} \\
x_{3}^{1}
\end{array}\right)=\left(\begin{array}{ccc}
0 & \frac{1}{L} & \frac{-1}{L} \\
\frac{-1}{C_{1}} & 0 & 0 \\
\frac{-1}{C_{2}} & 0 & \frac{-1}{R C_{2}}
\end{array}\right)\left(\begin{array}{l}
x_{1} \\
x_{2} \\
x_{3}
\end{array}\right)+\left(\begin{array}{c}
\frac{1}{L} \\
0 \\
0
\end{array}\right) V_{d} \\
A=A_{1} D+A_{2}(1-D) \\
B=B_{1} D+B_{2}(1-D)
\end{gathered}
$$

$A=\left(\begin{array}{ccc}0 & \frac{1}{L} & \frac{-(1-D)}{L} \\ \frac{-1}{C_{1}} & \frac{-D}{\left(R_{i} C_{1}\right.} & 0 \\ \frac{(1-D)}{C_{2}} & 0 & \frac{-1}{R C_{2}}\end{array}\right) B=\left[\begin{array}{c}\frac{(1-D)}{L} \\ \frac{D}{R_{i} C_{1}} \\ 0\end{array}\right] C=\left(\begin{array}{lll}0 & 0 & 1\end{array}\right)$

Using Laplace transformation: 


$$
\begin{gathered}
S \hat{x}(s)=A \hat{x}(s)+\left[\left(A_{1}-A_{2}\right) \times+\left(B_{1}-B_{2}\right) V\right] \hat{d}(s) \\
\hat{x}(s)=[S I-A]^{-1}\left[\left(A_{1}-A_{2}\right) \times+\left(B_{1}-B_{2}\right) V\right] \hat{d}(s) \\
\frac{\hat{v}_{0}(s)}{\hat{d}(s)}=C[S I-A]^{-1}\left[\left(A_{1}-A_{2}\right) \times+\left(B_{1}-B_{2}\right) V_{d}\right]+\left(C_{1}-C_{2}\right) X \\
S I-A=\left(\begin{array}{ccc}
S & \frac{-1}{L} & \frac{(1-D)}{L} \\
\frac{-1}{C_{1}} & S+\frac{D}{\left(R_{i} C_{1}\right)} & 0 \\
\frac{-(1-D)}{C_{2}} & 0 & S+\frac{1}{R C_{2}}
\end{array}\right)
\end{gathered}
$$

Removing $R_{i}$ terms:

$$
\frac{\hat{v}_{o}}{\hat{d}}=V_{g}\left[\frac{-S L\left(\frac{2-D}{(1-D)^{2}}\right)+R}{S^{2} L R C_{2}+S L+R(1-D)^{2}}\right]
$$

\section{Circuit Averaging Technique}

In ON condition:

$$
\begin{aligned}
& V_{L}(t)=V_{g}(t) \\
& i C_{1}(t)=i_{g}(t)-i(t) \\
& i C_{2}(t)=\frac{-V_{0}}{R}
\end{aligned}
$$

OFF condition:

$$
\begin{aligned}
& V_{L}(t)=2 V_{g}(t)-V_{0}(t) \\
& i C_{1}(t)=i_{g}(t) \\
& i C_{2}(t)=i_{g}(t)-\frac{V_{0}}{R} \\
& V_{L}(t)=D V_{g}(t)+D^{1}\left(2 V_{g}(t)-V_{0}(t)\right) \\
& i C_{1}(t)=D\left(i_{g}(t) \pm i(t)\right)+D^{1}\left(i_{g}(t)\right) \\
& i_{C 2}(t)=D\left(\frac{-V_{0}}{R}\right)+D^{1}\left(i_{g}(t)-\frac{V_{0}}{R}\right.
\end{aligned}
$$

Introducing perturbations:

$$
\begin{aligned}
& V_{g}(t)=V_{g}+\hat{v}_{g}(t) \\
& v_{0}(t)=V_{0}+\hat{v}_{0}(t) \\
& i_{g}(t)=I_{g}+\hat{i}_{g}(t) \\
& i(t)=I+\hat{i}(t)
\end{aligned}
$$

Adding perturbations and eliminating DC terms:

$$
\begin{aligned}
& S \hat{i}(s)=(2-D) \hat{v}_{g}(s)+\hat{d}(s)\left[V_{0}-V_{g}\right]-D^{1} \hat{v}_{0}(s) \\
& C_{1} S \hat{v}_{g}(s)=\hat{i}_{g}(s)-D \hat{i}(s)-\hat{d}(s) I \\
& C_{2} S \hat{v}_{0}(s)=D^{1} \hat{i}_{g}(s)-\hat{d}(s) I_{g}-\frac{\hat{v}_{0}(s)}{R}
\end{aligned}
$$

We assume $\hat{v}_{g}(s)=0$.

Using Dc terms:

$$
\begin{aligned}
& V_{0}=V_{g}\left(\frac{2-D}{1-D}\right) I_{g}=\frac{V_{0}}{R D^{1}} I=\frac{V_{0}}{R D D^{1}} \\
& \frac{\hat{v}_{0}(s)}{\hat{d}(s)}=V_{g}\left[\frac{-S L\left(\frac{2-D}{(1-D)^{2}}\right)+R}{S^{2} L R C_{2}+S L+R(1-D)^{2}}\right]
\end{aligned}
$$

If:

$C_{1}=C_{2}=2 \times 10^{-6}, L=10 \times 10^{-3}, R=100 \Omega$

$$
\frac{\bar{v}_{0}(s)}{\bar{d}(s)}=\left[\frac{S(-2.16)+3600}{S^{2}(0.000002)+S(0.01)+25}\right]
$$

The transfer functions obtained in the state space averaging and circuit averaging technique are the same and it is shown in the Equation 3 and 8.

\section{Frequency Response Analysis of Luo Converter}

A bode plot is a graph of the transfer function of a linear time in variant system versus frequency plotted with a $\log$ frequency axis to show the system's frequency response. The transfer function (control to output voltage) obtained from the modeling methods as shown in Equation 9 is used to obtain bode plot, step response and pole zero plot.

The transfer functions derived by state space averaging technique and circuit averging technique are the same. Derived transfer function can be used to determine the stability of the system. It is also used to obtain the closed response of the system. Bode plot drawn from these transfer function shows the operating frequency of the converter and the phase and gain margin tells about the stability of the system.

Figure 4 and 5 shows the step response obtained from the transfer derived. Figure 6 and 7 shows the bode plot for the derived transfer function and their gain margin and phase margin are determined. Figure 8 shows the pole zero plot of the converter. It also shows that the zero lies on the right half of the S-plane. So the system is unstable. A good understanding of the frequency-domain behavior of power converters is achieved. 


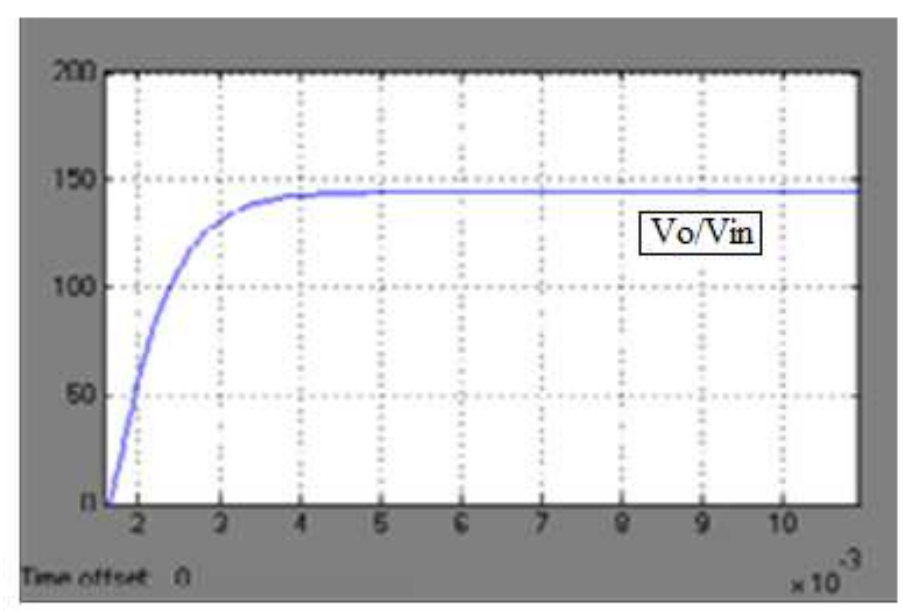

Fig. 4. Step response of input to output transfer function

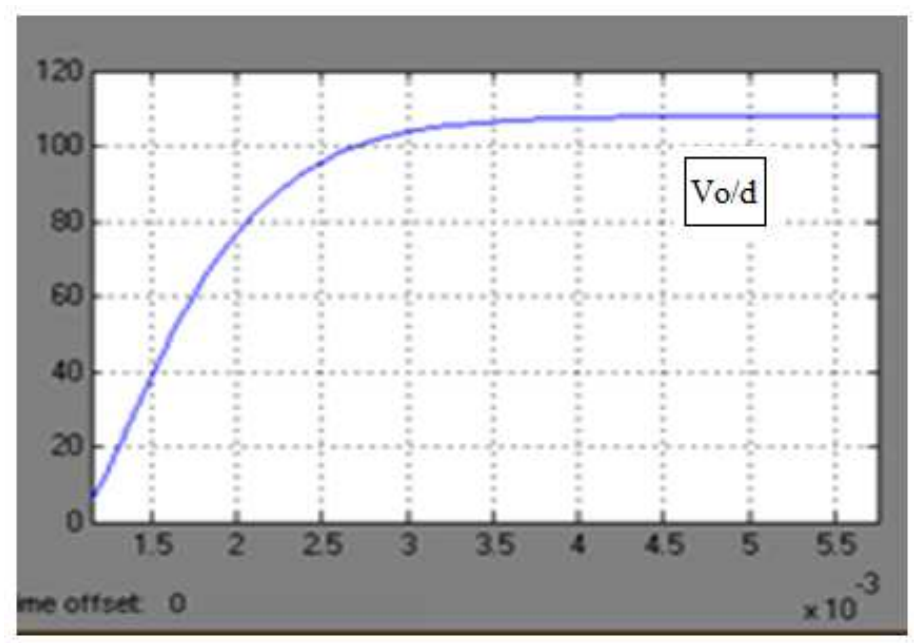

Fig. 5. Step response of duty cycle to output transfer function

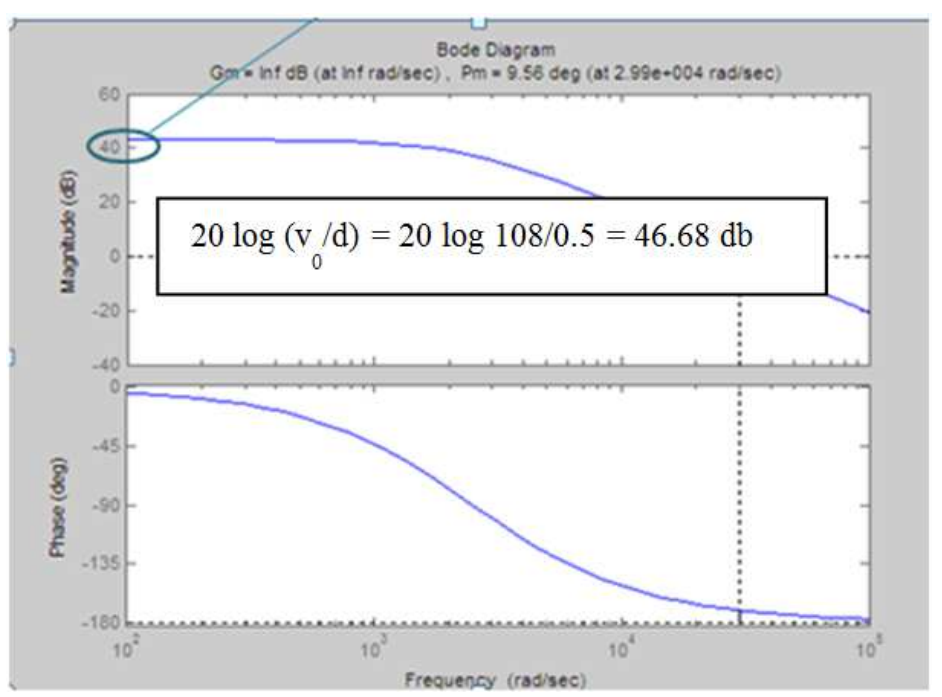

Fig. 6. Bode plot of duty cycle to output transfer function 


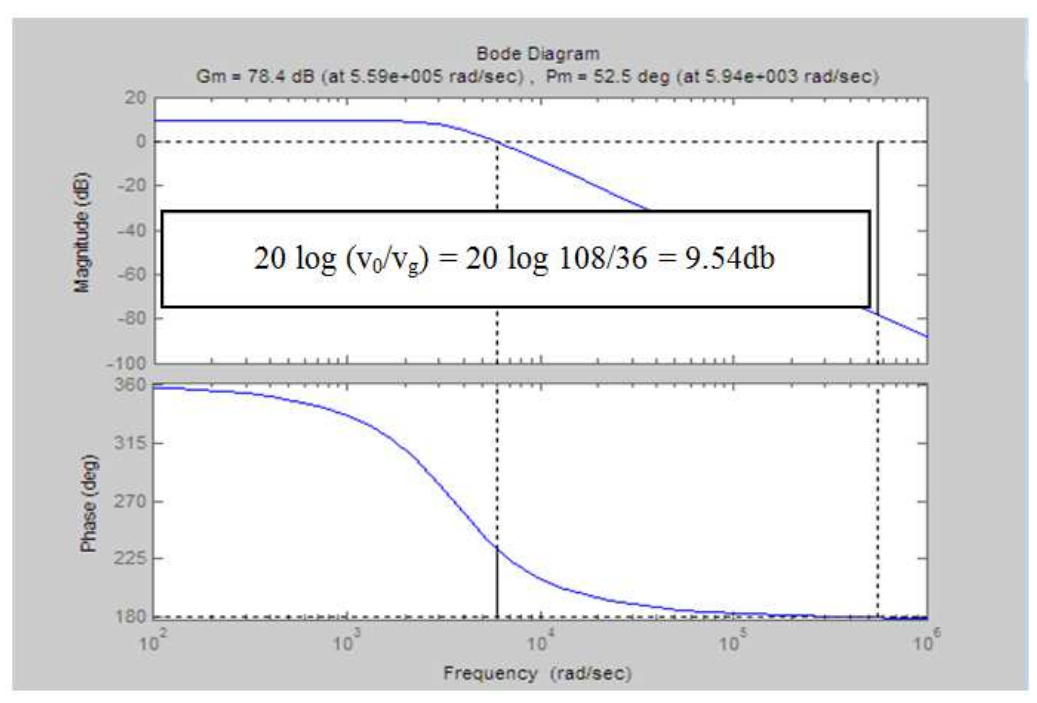

Fig. 7. Bode plot of input to output transfer function

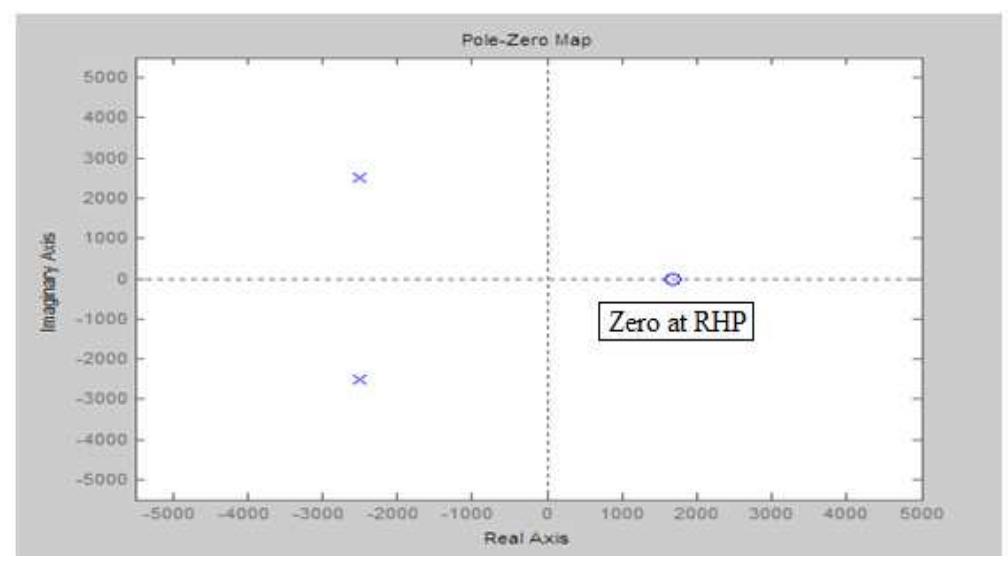

Fig. 8. Pole-zero plot for input to output transfer function

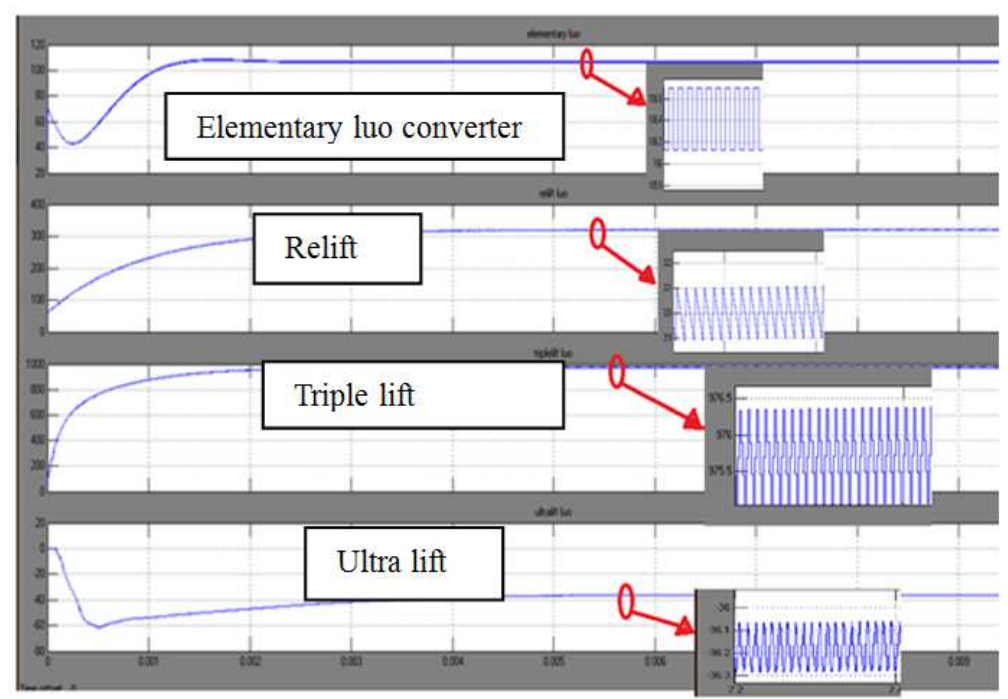

Fig. 9. Simulated output voltage ripple of voltage lift Luo converter 


\section{Analysis of Voltage Lift Luo Converter}

Different positive super lift converters are compared with the conventional boost converter and their output voltage ripples are analyzed.

Figure 9 shows the simulated output voltage ripple of voltage lift Luo converter. It is found the ripples are very less in elementary luo converter and stresses on the switches are also very less compared to voltage lift luo converter.

\section{Efficiency Model of Elementary Voltage Lift Luo} Converter Using Simulink

$$
\begin{aligned}
& \mathrm{I}_{\text {inoff }}=\mathrm{I}_{11 \text { off }}=\mathrm{I}_{\text {cloff }} \\
& \mathrm{I}_{\text {inon }}=\mathrm{I}_{11 \text { lon }}+\mathrm{I}_{\text {clon }} \\
& \mathrm{P}_{\text {cond }}=\mathrm{I}_{\text {out }}{ }^{2} * \mathrm{R}_{\text {DSon }} \frac{\text { Vout }}{\text { Vin }} \\
& \mathrm{I}_{\text {in }}=(2-\mathrm{k}) \mathrm{I}_{11} \mathrm{P}_{\mathrm{SW}}=\frac{\operatorname{Coss}^{2} \mathrm{f}}{2} \\
& \text { Turn on loss }=\frac{(\operatorname{Coss}+\mathrm{Cp}) \mathrm{V}^{2} \mathrm{f}}{2}
\end{aligned}
$$

Equation 10-12 gives conduction and switching losses of the converter. Figure 10 shows efficiency modeling of elementary luo converter with Matlab/simulink. Table 1 gives the comparison between state space averaging and circuit averaging technique. Table 2 gives a brief outlook on different luo converters. Table 3 shows that the efficiency obtained remain same both theoretically and results obtained through modeling.

\section{Voltage Mode Controlled Luo Converter}

Designing of PI Controller Using ZieglerNichols Tuning Procedure

The Ziegler-Nichols tuning method is performed by setting the $I$ (integral) and $D$ (derivative) gains to zero. The "P" (proportional) gain, $K_{p}$ is then increased (from zero) until it reaches the ultimate gain $K_{u}$, at which the output of the control loop oscillates with a constant amplitude. $K_{u}$ and the oscillation period $T_{u}$ are used to set the P, I and D gains depending on the type of controller used. Using Ziegler Nichols tuning method, the transfer function of the PI controller is:

$G_{P}(s)=\frac{0.0000087127 s+0.0099684}{0.000874037 s}$

$G_{P}(s) \cdot T_{F}(s)$

$=\frac{-\left(0.000000706725 s^{2}+11.25+0.00502875 s\right.}{0.0000000002094 s^{3}+0.000010471 s^{2}+0.0261775 s}$

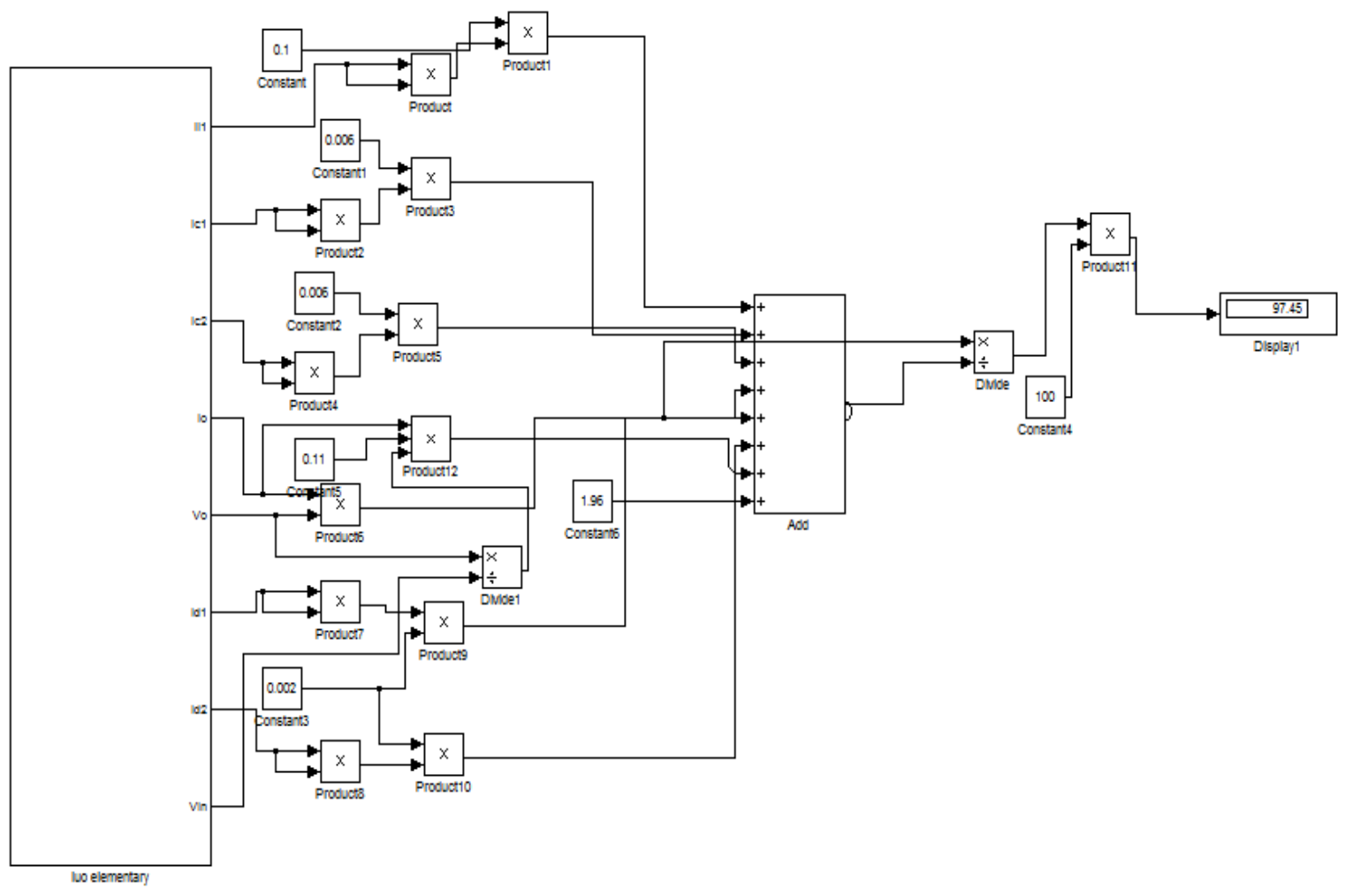

Fig. 10. Efficiency modeling of Elementary luo converter 


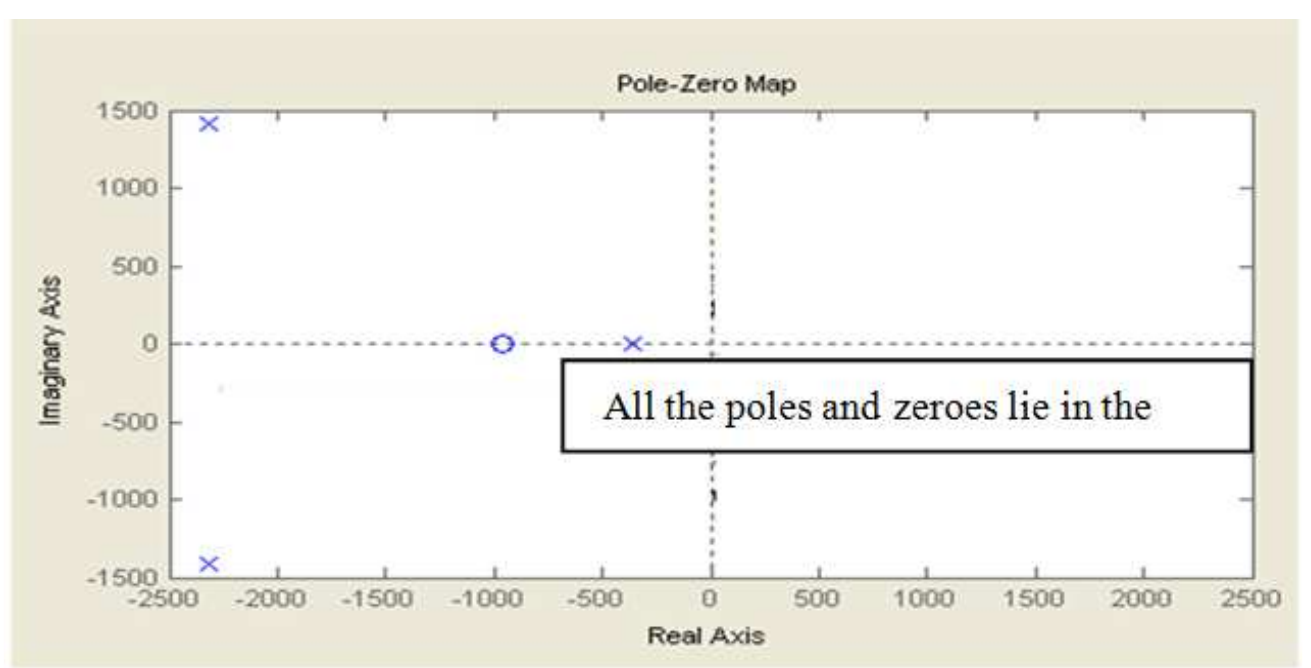

Fig. 11. Plot zero plot-closed loop elementary Luo converter

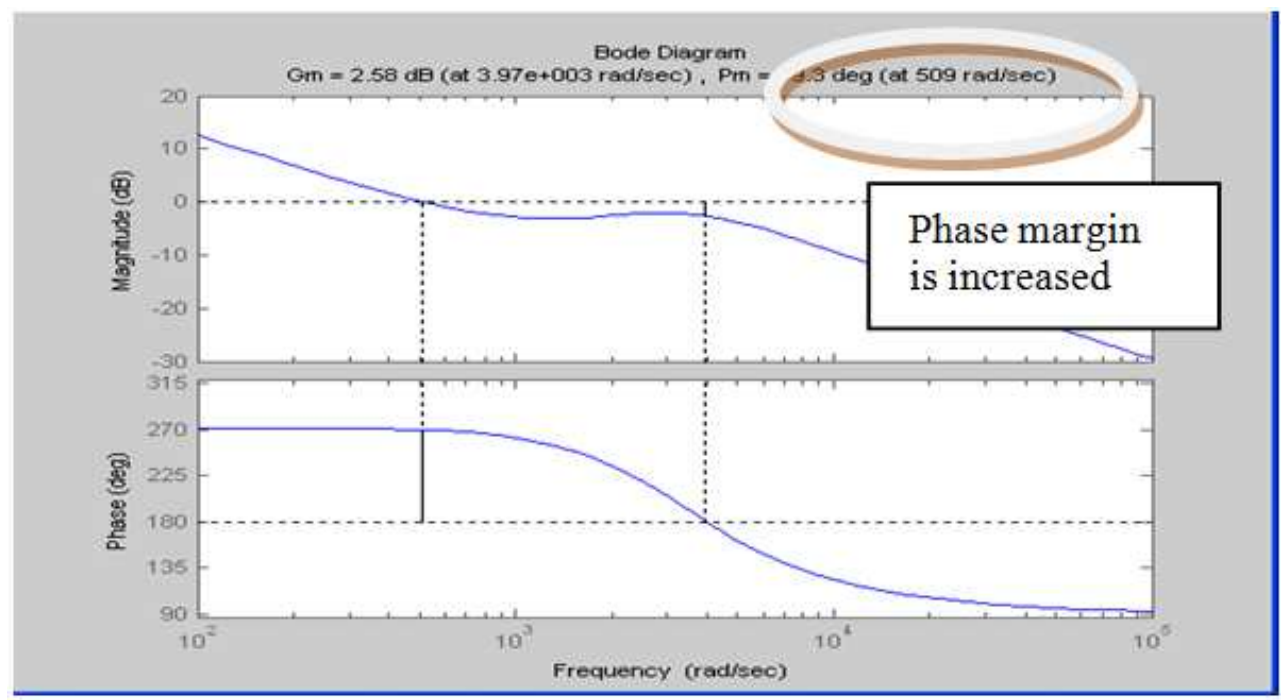

Fig. 12. Bode plot of closed loop Elementary Luo converter

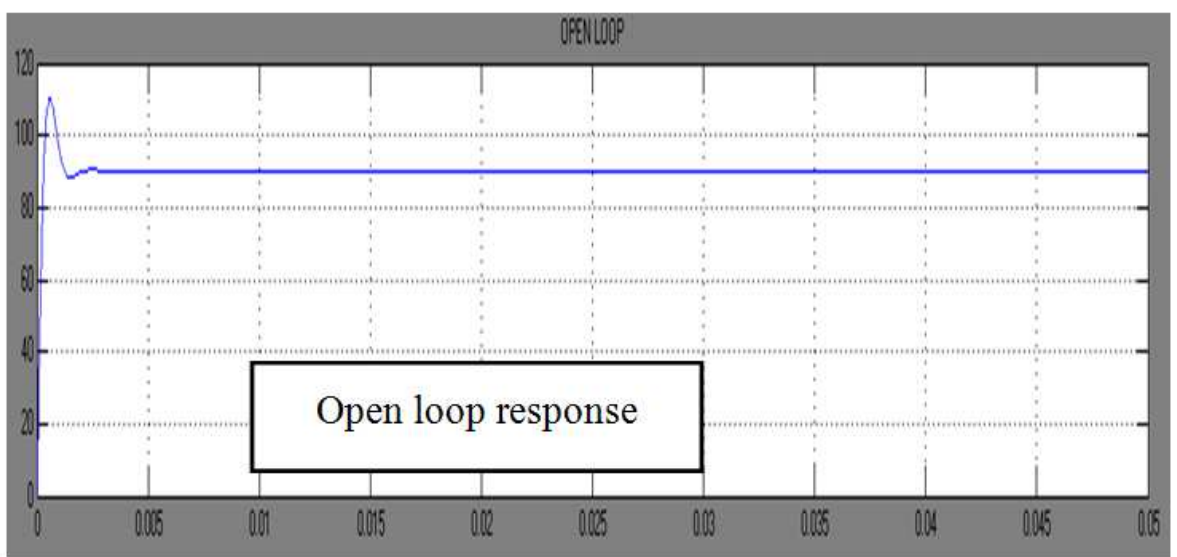

Fig. 13. Open loop response of Elementry Luo converter 


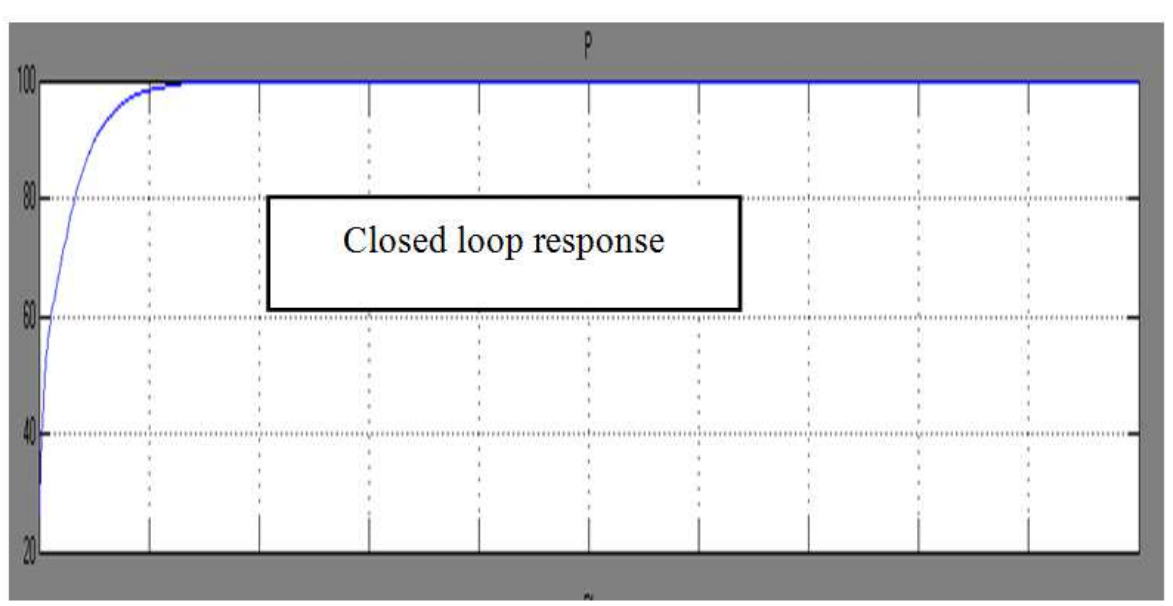

Fig. 14. Closed loop response-tuning the PI controller

Table 1. Comparison between state space averaging and circuit averaging

\begin{abstract}
State space averaging technique
This approach offers a clear insight into the quantitative nature of basic averaging approximation. This method is tedious when the converter circuit contains a large number of elements.

The linearised models, obtained from state-space averaging, do not predict the large-signal stability information and are only sufficient to predict small-signal stability They are more general and powerful for analyzing and controlling both steady state behavior and small signal perturbations from it.
\end{abstract}

\section{Circuit averaging technique}

This approach is using an averaging technique is based on equivalent circuit manipulations, resulting in a single equivalent circuit.

Huge approximations for large circuits.

Analysis and synthesis can be used in the fullest extent for the design of regulators incorporating switching converters.

May not provide complete solution for analyzing and controlling the dynamics of circuits.

Table 2. Comparison of different Luo converter

\begin{tabular}{|c|c|c|}
\hline DC-DC converter & Advantage & Disadvantage \\
\hline Boost converter & Effective boosting for LCD backlights and flashlights. & Large amount of ripples in output voltage. \\
\hline Elementary & Cheap topology and high output voltage & Cannot be independently used for very high \\
\hline Luo Converter & & step up applications like in HEV and smart grid \\
\hline Superlift & High gains using geometric progressions & Difficult to design because of complexity to \\
\hline Luo Converter & & resonant circuits \\
\hline Relift & High power density and high efficiency & Complicated circuit. Circuitbecomes bulky. \\
\hline Luo Converter & & Cost will be higher compared to relift and elementary luo \\
\hline $\begin{array}{l}\text { Ultra Lift } \\
\text { Luo Converter }\end{array}$ & High voltage transfer gain. High output voltage & $\begin{array}{l}\text { Negative output voltage. Converter output has to } \\
\text { be inverted .Circuitry becomes Large }\end{array}$ \\
\hline
\end{tabular}

Table 3. Efficiency comparison

\begin{tabular}{lll}
\hline LUO converter & Theoretical efficiency & Simulated efficiency \\
\hline $\begin{array}{l}\text { Elementary } \\
\text { luo converter }\end{array}$ & $98.1 \%$ & $97.45 \%$ \\
\hline
\end{tabular}

Table 4. Phase margin-luo converter

\begin{tabular}{lll}
\hline Parameter & $\begin{array}{l}\text { Open loop } \\
\text { luo converter }\end{array}$ & $\begin{array}{l}\text { Closed loop } \\
\text { luo converter }\end{array}$ \\
\hline Phase margin & $9.56^{\circ}$ & $89.53^{\circ}$ \\
\hline
\end{tabular}

Equation 13 gives the transfer function of PI controller using Ziegler Nichols second tuning method. Equation 14 gives the closed loop transfer function of elementary loop converter. Figure 11 and 12 shows the pole zero plot and bode plot of the closed loop system.
We can see all the poles and zeroes of the transfer functions are lying on the left half of the s plane. As a result of this, the converter is stable. Also, from the bode plot of the closed loop transfer function we can see that, the phase margin has been raised to high positive value. Also, the gain margin is positive which indicates the stability of the converter under closed loop control. Thus the controller's characteristics provide increased phase margin and improved stability to a DC-DC converter. Table 4 shows the improvement in phase margin from open loop to closed loop system.

As, from the pole zero plot, we can see all the poles and zeroes of the transfer function are lying on the left half of the s plane the converter is stable. Also, from the bode plot of the closed loop transfer function we can see 
that, the phase margin has been raised from negative to a marginally high positive value. Also, the gain margin is positive which indicates the stability of the converter under closed loop control.

Figure 13 and 14 shows the response obtained from the open loop and closed loop system. Overshoot in the open loop response is suppressed with the help of PI controller in the closed loop system.

\section{Conclusion}

With the increasing demand of renewable energy sources, we have proposed superlift series of luo converter instead of boost converter, which is typically used in hybrid electric vehicle. For choosing the best converter out of the super lift series of luo converter, voltage ripple analysis, stress on switches of the converter and efficiency modeling were done on elementary luo converter, relift luo converter and triple lift luo converter. For our application of hybrid electric vehicle, we found elementary luo converter to be highly suitable.

Modeling of elementary luo converter has been done using state space averaging method and circuit averaging technique. Using the transfer function obtained, bode plot was drawn for input to output voltage transfer function as well as duty cycle to output voltage transfer function. The poles and zeroes obtained for the transfer function are in the right half of the $\mathrm{S}$ plane as compared to buck converter which has zeroes in the left half of the $S$ plane.

Based on the frequency response analysis, the phase margin obtained is very low $(2.53 \mathrm{deg})$ and the gain margin is infinity (inf) which shows that the system is unstable. So we propose to design a closed loop control for the luo converter in order to make the system stable. A PI controller was designed using Ziegler Nichols tuning method. The PI controller was cascaded with the open loop transfer function obtained from circuit averaging technique as well as state space averaging technique. A closed loop was designed after cascading. The poles and zeroes of the transfer function lie on the left half of the s plane which shows the stability of the closed loop control of the converter, also the phase margin has been raised to $89.3 \mathrm{deg}$ and the gain margin is also positive. All these results prove that the closed loop control of the elementary luo converter is stable.

\section{Funding Information}

The authors have no support or funding to report.

\section{Author's Contributions}

Divya Navamani Jayachandran: Actively participated in modelling of Luo converter and closed loop analysis.

Vijayakumar Krishnaswamy: Contributed to the writing of the manuscript.
Lavanya Anbazhagan: Participated in simulating the converter in MATALAB/Simulink and analysing the same.

Karthikeyan Dhandapani: Contributed in frequency response analysis of Luo converter.

\section{Ethics}

This article is original and contains unpublished material. The corresponding author confirms that all of the other authors have read and approved the manuscript and no ethical issues involved.

\section{References}

Kazimierczuk, M.K. and D. Czarkowski, 1993. Application of the principle of energy conservation to modeling the PWM converters. Proceedings of the 2nd IEEE Conference on Control Applications, Sep. 13-16, IEEE Xplore Press, Vancouver, BC, pp: 291-296. DOI: 10.1109/CCA.1993.348274

Luo, F.L. and H. Ye, 2001. DC/DC conversion techniques and nine series Luoconverters. In: Power Electronics Handbook, Rashid, M.H. (Ed.), CA, Academic, San Diego, pp: 17-17.

Luo, F.L., 1999a. Negative output Luo converters: Voltage lift technique. Proc. Inst. Elect. Eng., 146: 208-224. DOI: 10.1049/ip-epa:19990302

Luo, F.L., 1999b. Positive output Luo converters: Voltage lift technique. Proc. Inst. Elect. Eng., 146: 415-432. DOI: 10.1049/ip-epa:19990291

Luo, F.L., 2000. Double-output Luo converters, an advanced voltage-lift technique. Proc. Inst. Elect. Eng., 147: 469-485. DOI: 10.1049/ip-epa:20000622

Luo, F.L., H. Ye and M.H. Rashid, 2002. Multiplequadrant Luo-converters. Proc. Inst. Elect. Eng., 148: 9-18. DOI: 10.1049/ip-epa:20020024

Middlebrook, R.D. and S. Cuk, 1970. A general unified approach to modelling switching-converter power stages. Proceedings of the Power Electronics Specialists Conference, Jun. 8-10, IEEE Xplore Press, Cleveland, OH, pp: 18-34. DOI: 10.1109/PESC.1976.7072895

Polivka, W.M., P.R.K. Chetty and R.D. Middlebrook, 1986. State-space average modeling of converters with parasitics and storage time modulation. Proceedings of the Power Electronics Specialists Conference, (ESC' 86), pp: 119-143.

Severns, R.P. and G. Bloom, 1985. Modern DC-to-DC Switchmode Power Converter Circuits. 1st Edn., Springer Netherlands, Springer, ISBN-10: 9401180873, pp: 30-42.

Vorpérian, V., 1990. Simplified analysis of PWM converters using model of PWM switch. Continuous conduction mode. IEEE Trans. Aerosp. Electron. Syst., 26: 490-496. DOI: 10.1109/7.106126 